\title{
EXPERIMENTALISMO E POLITIZAÇÃO NA DRAMATURGIA BRASILEIRA DA DÉCADA DE 1960: DO SEMINÁRIO DE DRAMATURGIA NO TEATRO DE ARENA À PEÇA MUTIRÃO EM NOVO SOL
}

\author{
Paulo Bio Toledo \\ Doutorando do Programa de Pós-graduação em Artes Cênicas da Escola de Comunicações e \\ Artes da USP (PPGAC ECA-USP) \\ Pesquisador do Laboratório de Investigação em Teatro e Sociedade (USP) \\ E-mail: paulo.v.bio@gmail.com \\ Paula Chagas Autran Ribeiro \\ Doutoranda do Programa de Pós-graduação em Artes Cênicas da Escola de Comunicações e \\ Artes da USP (PPGAC ECA-USP) \\ Pesquisadora do Laboratório de Investigação em Teatro e Sociedade (LITS) \\ E-mail: paulautranch@gmail.com
}

Seguindo a tradição iniciada com os Seminários de Dramaturgia do Teatro de Arena, Nelson Xavier escreveu Mutirão em Novo Sol em 1961, em coautoria com Augusto Boal, sobre uma revolta de lavradores ocorrida em 1959 no interior de São Paulo. Tanto o Seminário do Arena quanto a peça representam momentos decisivos da modernização e do engajamento do teatro no Brasil. Por meio da análise destes acontecimentos, o trabalho busca debater algumas das questões consideradas centrais neste momento de inflexão do teatro nacional.

\section{Palavras-chave}

Teatro de Arena; Seminário de dramaturgia; CPC; MCP; Nelson Xavier.
According to the tradition begun with the Seminários de Dramaturgia do Teatro de Arena (Playwriting Seminars of Teatro de Arena), Nelson Xavier wrote Mutirão em Novo Sol in 1961, co-authored with Augusto Boal, about a peasant's rebellion that took place in 1959 in a country town of São Paulo. Both the Seminários de Dramaturgia and the play represent key moments on the modernization and on the engagement of brazilian theatre. By analyzing these events, this academic paper seeks to debate some of the issues considered centrals in this time of inflection of the national theatre.

Keywords

Teatro de Arena; Playwriting Seminars; CPC; MCP; Nelson Xavier. 


\section{Seminários de Dramaturgia}

O Seminário de Dramaturgia do Teatro de Arena foi o primeiro projeto de estudo e produção sistemática de uma dramaturgia nacional moderna. Fundado em 1958,"funcionou com regularidade semanal por aproximadamente dois anos, com interrupções." (GUIMARÃES, 1978 , p. 67). Sua contribuição para uma mudança nos caminhos da modernização do teatro brasileiro é inestimável. Uma geração de dramaturgos com atuação no teatro, no cinema e na televisão foi influenciada pelos debates que ali ocorreram. Na forma de um encontro semanal de leitura e debate sobre textos dos jovens autores, o Seminário nasceu de uma evolução do curso de dramaturgia ministrado nos anos anteriores por Augusto Boal e mantém vínculos profundos com a prática artística, política e pedagógica das encenações produzidas no Teatro de Arena.

O Seminário não era restrito aos integrantes da companhia. Estudiosos convidados ampliavam os temas discutidos pelos dramaturgos. Do Seminário saíram sete textos de autores nacionais - entre eles Chapetuba Futebol Clube, de Oduvaldo Vianna Filho, o Vianinha, e Revolução na América do Sul, de Boal - e também uma nova maneira de produção da escrita dramática e de espetáculos teatrais. $\mathrm{A}$ grande novidade estava na forma compartilhada com que o dramaturgo concebia seu texto, em meio a debates políticos, estéticos e artísticos. Construía-se ali uma pedagogia dramatúrgica sem precedentes no teatro do país.

O sentido geral da novidade histórica do Seminário de Dramaturgia se liga, assim, a um deslocamento da função e do trabalho da dramaturgia (a partir de sua conexão radical com a prática) e de uma inédita coletivização da escrita, experiência até então impensável na linha de modernização do teatro brasileiro, que se tornava hegemônica a partir do modelo de maior desenvolvimento empresarial do Teatro Brasileiro de Comédia (TBC). $O$ texto e a cena nasciam interligados, sendo seu tema - e sua forma de representação - problematizados a um só tempo.

Além disso, o trabalho do dramaturgo se confundia com outras operações do teatro, podendo ser ele também ator, diretor e técnico de seus espetáculos e dos espetáculos dos outros integrantes do Seminário. Estava em jogo, portanto, uma reelaboração da função do dramaturgo, que pensava, ao mesmo tempo, a necessidade de uma consciência formativa e metodológica.

Em meio às discussões das peças e de suas montagens, foi empreendido no Seminário um amplo esforço de reflexão metodológica sobre uma dramaturgia brasileira de orientação nacional e popular, que gerou a necessidade de criar peças que refletissem o momento histórico no qual estavam inseridos. A teorização sobre a relação entre dramaturgia e a história atual surge no entrecruzamento da escrita da peça e sua efetivação no palco. Para alcançar essa interação, que só pode se dar no campo de uma crítica da teatralidade, tornou-se crucial o estudo detalhado de cada um de seus aspectos produtivos (o trabalho do ator, a cenografia, a escrita etc.) de modo que a perspectiva do processo de aprendizagem passasse a orientar o grupo em suas realizações culturais.

O que se desenha a partir de então é um deslocamento importante no que se refere ao modo convencional de encenar peças. Ao contrário dos diretores tradicionais, que criam os movimentos do palco segundo "marcas", após 
os atores decorarem suas falas, Augusto Boal põe em prática um tipo de ensaio em que o processo teatral parte do estudo do material feito em grupo. Com todas as contradições ideológicas que o conceito envolve, o pensamento nacional-popular significava no Arena daquele momento um impulso para uma prática conectada com as forças mais progressistas da época, nos termos da pesquisadora Maria Silvia Betti:

Nesse período, a indústria de bens culturais de massa era incipiente, e a ideia de um projeto de cultura nacional-popular não havia, ainda, sido cooptada pelos meios de comunicação, constituindo-se, portanto, em perspectiva de abertura para uma nova forma de atuação no campo cultural. Diante desse contexto, povo e nação, entendidos como elementos conceituais positivos e inovadores, trazem em si a perspectiva da renovação da práxis teatral e da integridade entre pensamento e atuação. Fortalece-se, assim, a referida visão crítica da história do teatro no Brasil, enquanto se desenvolve uma enriquecedora forma de atuação política e cultural. (BETTI, 1997, p. 16)

No Seminário de Dramaturgia os integrantes do Teatro de Arena assumem, pela primeira vez, um projeto estético totalizante, que une todas as áreas das realizações do grupo. Com esse direcionamento, a dramaturgia surge como o lugar de organização mais geral dos trabalhos. Torna-se intensa a busca por uma linguagem teatral genuinamente brasileira, tanto na fala quanto na atuação, como a realizada por algumas companhias de teatro popular. Torna-se imprescindível o engajamento, que vem ao encontro dessa necessidade de formação que não é apenas do grupo, mas de um teatro que se pensa dentro do conjunto do teatro da cidade e do país. O dramaturgo precisa ser um pesquisador, estudioso de uma arte engajada social e politicamente, e para isso faz-se necessário repensar o conjunto de sua história.

Em torno dos integrantes do Seminário parecia haver um consenso de que para se discutir teatro era agora necessário se discutir também a realidade nacional. Essa tomada de posição vai além dos temas e influencia diretamente a feitura das peças que serão discutidas. Radicaliza-se o projeto de um teatro engajado socialmente, de sentido nacional-popular, que traz para dentro da sala de ensaio a discussão política e a reflexão sobre o momento social. A ênfase dos debates, desde o início, estava no conteúdo das peças analisadas e na visão de mundo que elas encerravam. Essa necessidade de problematizar assuntos amplos, que envolviam conjuntura, acabará por aumentar a contradição entre o projeto ideológico e os modelos formais, ainda predominantemente de ordem dramática.

Quando percebem que seus interesses críticos encaminhavam o projeto para uma reflexão sobre uma teatralidade que transborda os limites do drama, os integrantes do Seminário se vêm obrigados a refletir sobre seus caminhos formais num sentido novo. Enquanto essa contradição não estava clara, a equipe constatava que a novidade principal do trabaIho do grupo era da ordem do conteúdo, como bem aponta Vianinha numa reflexão sobre o período:

Enquanto as outras companhias, sem muito para dizer de autêntico, comercializavam a sua forma, o Arena comercializava seus conteúdos, usando no público sua área mais urgente de indagações pelo mundo. Os problemas que menos distância possuíam da realidade social formam abordados. As mediações longínquas foram abolidas.

(VIANINHA, 1983, p. 91) 
Como fica claro na citação, a estruturação do programa de estudos veio em sintonia com a prática, atendendo às possibilidades de autores "jovens de pouca idade sem experiência de vida" (BOAL, 2000, p. 150). O mais importante era que todos de fato "estudaram, discutiram, escreveram" (BOAL, 1980, p. 149). Na prática dos encontros do Seminário, a dramaturgia era entendida como concreção de valores políticos e teorizantes. Cada texto era analisado como um trabalho dialético, o que pedia, no mínimo, uma união à interpretação. A prática do Seminário ia assim, muito além da mera aquisição de técnica literária. $O$ texto era um meio de estudos para o grupo. Os integrantes permitiam-se levar ao palco peças que não tinham uma estrutura de obra acabada, mas cujo tema ou personagem central interessava do ponto de vista político. Não havia, nesse sentido, uma fórmula de resultados pré-estabelecida. A pesquisa se dava por tentativa e erro.

O Seminário superava, assim, a mera aplicação das estudadas leis do drama, em favor de uma perspectiva laboratorial. Os sete textos produzidos a partir do Seminário aproximamse muito do universo de atuação, pois ou foram escritas para os atores ou por eles. Flávio Migliaccio até então nunca havia escrito. Nelson Xavier e Milton Gonçalves tiveram seus estudos ali analisados, ainda que não encenados. Buscava-se uma atitude autoral do conjunto da equipe. A grande descoberta do Seminário era simples e rara: o trabalho do dramaturgo é sempre coletivo, mesmo que escreva em casa. Mais do que o estudo da dialética aplicada ao teatro, a contribuição modelar do Seminário se forma a partir de sua mobilidade constante entre aprendizagem e produção, entre teoria e prática, entre arte e história.
Os integrantes do Arena tentavam com sua prática teatral desnudar as diferenças de classe e as fissuras sociais do país, também presentes no mundo da cultura, o que levaria o próprio grupo a rachar diante de um aprendizado que impunha a todos uma reflexão sobre a função social do teatro. A radicalização da postura de Vianinha e de Chico de Assis que os conduz ao CPC é, entretanto, uma consequência de um trabalho anterior. Tanto das excursões com as peças nacionais que encenam por meio do Seminário, quanto do efeito modelar de uma peça radicalmente épica como Revolução na América do Sul, de Boal, que teve sua estreia em 1960. Guarnieri é quem aponta o vínculo indissolúvel entre as pesquisas do Seminário e do CPC:

O Seminário pode ter sido, por exemplo, o primeiro espectro desta mistura de tendências que vai aflorar no CPC. Muitas das posições discutidas no Seminário passam a ser o centro de debates internos do CPC e muitas passam a ser a linha de ação do movimento. (In: PEIXOTO, 1985, p. 106)

A verdadeira dialética do Seminário haveria de se realizar fora dele, num lugar em que o conteúdo e a forma teatral uniam-se dialeticamente, em que a história deveria ser produzida de modo livre. O drama era, para isso, uma técnica insuficiente. Abria-se de vez a necessidade de uma encenação épico-dialética conectada ao momento brasileiro. Se é verdade que Brecht, com sua negatividade radical, não era um modelo fácil a ser adotado num país que há pouco realizava seus primeiros dramas, eram também verdade que uma teatralidade dialética e popular deveria ser inventada. Foram essas as coordenadas que o Seminário forneceu ao CPC, gerando uma nova pesquisa laboratorial nas ruas que seria interrompida 
com o golpe de 1964.

Por conta de seu caráter exemplar, o Seminário de Dramaturgia do Teatro de Arena acabou sendo replicado em diferentes cidades do país, como Rio de Janeiro, Porto Alegre, entre outras, tornando-se um modelo para todo escritor de teatro da década de 60 . Em paralelo ao Seminário de Dramaturgia, os artistas do Arena fazem viagens para conhecer de perto a realidade nacional, escrevem textos teóricos sobre essas experiências, e reposicionam o espectro de atuação possível de um grupo teatral. Essa nova forma de organização artística e política acabará ensejando a criação do CPC em 1960, e uma parceria profícua com diferentes movimentos sociais, como o Movimento de Cultura Popular (MCP), de Recife e deixará um legado muito além dos palcos. de Recife e deixará um legado muito além dos palcos.

\section{Mutirão em Novo Sol}

No momento dessa passagem entre os processos de aprendizagem do Seminário e as experiências de democratização da cultura no CPC e MCP, encontra-se uma peça decisiva para todo o período. Trata-se de Mutirão em Novo Sol, peça escrita em 1961 por Nelson Xavier em parceria com Augusto Boal ${ }^{1}$ (XAVIER, 2015). Embora esquecido por mais de cinquenta anos, é um texto de importância seminal nos processos de engajamento, popularização do teatro e experimentalismo artístico que marcaram os anos anteriores ao Golpe Militar de 1964. Com efeito, a peça contém tanto aquele espírito laboratorial dos Seminários como a vontade de ultrapassar a ideia de
Mutirão em Novo Sol foi motivo de ao menos três montagens históricas e mobilizou alguns dos principais movimentos culturais do período, como o Teatro de Arena, o Centro Popular de Cultura (CPC) de São Paulo, o Movimento de Cultura Popular (MCP) de Pernambuco e, por fim, o importante CPC da Bahia, onde uniu setores de teatro e cinema em um tipo ainda desconhecido de linguagem híbrida politizada. Os espetáculos atingiram milhares de espectadores em um espaço curto de tempo, protagonizando significativos eventos como o I Congresso Nacional de Lavradores e Trabalhadores Agrícolas em Belo Horizonte (SANTOS, 1962), temporada no Teatro Santa Isabel em Recife (MENDONÇA, 1968, p. 154), apresentação em Brasília a convite do presidente João Goulart (COELHO, 2002, p. 33) e representações para multidões de lavradores pobres de Pernambuco, Paraíba e Bahia.

A estrutura da peça é organizada a partir do julgamento do lavrador Roque Santelmo Filho por "subversão" e "incitação à desordem" (XAVIER, 2015). No banco dos réus, Roque narra os eventos passados, que são apresentados em flashbacks e entremeados por comentários e debates no tempo do julgamento. Vemos então todo o histórico da revolta coletiva de lavradores arrendatários expulsos da terra pelo proprietário Coronel Porfírio. Após tentarem a inócua intervenção da lei, os camponeses, em um gesto espontâneo e coletivo, saqueiam o armazém, fundam uma União e decidem lutar pela terra. Em resposta, a Polícia, o Exército, a Igreja e os burocratas do Estado se aglutinam em torno do Coronel para manter a ordem com violência. Por fim, a Justiça revela ua parcialidade de classe e condena Roque até

\footnotetext{
1 Também teve a colaboração de integrantes do Teatro de Arena de São Paulo da época, como Benedito Araújo, Hamilton Trevisan e Modesto Carone.
} 
que ele interrompa a rebelião. A resposta é um gesto coral dos lavradores presentes que se levantam e entoam a canção do Arranca capim, símbolo de sua resistência. Roque, então, afirma a proporção coletiva, de classe, que o evento ganhou: "Senhor Juiz, essa gente não para nunca” (XAVIER, 2015, p. 79).

A figura de Roque é inspirada no líder camponês Jôfre Correa Neto, que em 1959 protagonizou um enorme levante de lavradores nas cidades de Jales e Santa Fé do Sul, interior de São Paulo (CHAIA, 1980; WELCH, 2010). Foi um movimento mais ou menos espontâneo de colonos expulsos sumariamente das terras arrendadas onde viviam e plantavam. O proprietário desejava criar gado de forma extensiva ali e indiferente aos apelos dos lavradores, queimava casas e expulsava à bala os que resistiam em sair. Estimulados por Jôfre e correndo risco de vida, muitos camponeses escolheram ficar e resistir. Em grandes grupos, arrancavam sistematicamente o capim plantado pelos jagunços do proprietário em suas quadras. A revolta, que ficou conhecida como "Arranca Capim", ganhou destaque nacional, e Jôfre tornou-se referência como agitador em um país que via crescer exponencialmente os conflitos no campo, apesar da alardeada modernização em marcha.

Mutirão em Novo Sol é um acontecimento decisivo para o processo de modernização do teatro no país - que ganhava um novo sentido com as experiências do Arena a partir de 1958 - e isso em vários aspectos. A começar pela novidade temática da peça: os conflitos sociais no campo. $O$ ineditismo não é o ângulo rural propriamente, afinal o interesse pitoresco da cultura pelo explorado, pelo sertanejo etc. já é antigo. A novidade é, antes, o pressentimento de que ali, na luta pela terra, na exploração do trabalho no campo, na miséria extremada se encontrava o principal ponto de tensão do Brasil, e que, por conseguinte, dali nasceria o futuro.

A organização de obras a partir desta matéria marginal passou a ser regra em quase toda a produção artística engajada nestes anos. No campo do teatro, os principais grupos de esquerda, como o Teatro de Arena de São Paulo e os grandes movimentos de democratização da arte, como o Centro Popular de Cultura (CPC) da UNE e o Movimento de Cultura Popular (MCP) de Pernambuco centralizavam suas criações cada vez mais no interesse pelas margens agrárias do país. Diversas montagens sobre o conflito pela terra ou sobre a exploração inacreditável do lavrador nas beiras do Brasil se sucediam nos anos anteriores ao golpe.

Sob a influência direta da montagem de Julgamento em Novo Sol${ }^{2}$ pelo MCP de Recife, Vianinha, criador e principal quadrodo CPC da UNE escreveu as peças Quatro quadras de terra (1963) e Os Azeredos mais os Benevides (1964). Em 1964, o CPC inauguraria seu novo teatro popular na sede da UNE com uma encenação da peça Os Azeredos mais os Benevides de Vianinha, com direção de Nelson Xavier - convidado especialmente devido ao sucesso de Julgamento em Novo Sol que viajou em turnê pelo Rio de Janeiro. No Teatro de Arena de São Paulo, O filho do cão, de Guarnieri, apresentado em 1964, pouco antes do golpe, foi uma tentativa deliberada de desenvolver temática e formalmente alguns tópicos de Mutirão (PEIXOTO, 1985, p. 56).

${ }^{2}$ A montagem de Mutirão em Novo Sol no MCP teve o título alterado para Julgamento em Novo Sol devido ao termo mutirão não ser utilizado no Nordeste. 
Mesmo no campo da modernização teatral não engajada, Antunes Filho estreou Vereda da salvação de Jorge Andrade no TBC em 1964 (que, por sinal, também virou filme no mesmo ano, com direção de Anselmo Duarte, que já havia dirigido $O$ pagador de promessas em 1962).

No campo do cinema, entre 1963 e 1964, Eduardo Coutinho estava embrenhado no sertão de Pernambuco com equipe do CPC e do MCP filmando Cabra marcado para morrer, sobre o assassinato do líder camponês João Pedro Teixeira na Paraíba. E em 1964 estrearam três filmes fundamentais do cinema brasileiro que têm como ângulo principal os conflitos do mundo rural brasileiro: Vidas secas, de Nelson Pereira dos Santos, Os fuzis, de Ruy Guerra, e Deus e o diabo na terra do sol, de Glauber Rocha. No caso de Glauber, a influência de Mutirão em Novo Sol é direta. Ele próprio tributa às experiências cinematográficas da montagem da peça no CPC da Bahia a influência decisiva para Deus e o diabo na terra do sol:

Em 1963, Orlando e Geraldo Sarno realizam o filme Rebelião em Novo Sol, com fotografia de Waldemar Lima, que integrava um espetáculo de Francisco de Assis sobre a reforma agrária. Montado em estilo eisensteniano-vertoviano, o filme influenciaria a epicidade de Deus e o Diabo na Terra do Sol. (ROCHA, 1982, p. 476)

Mesmo após a intervenção militar, a temática das margens em luta no sertão mantevese por alguns anos como fantasmagoria do espírito revolucionário (Cf. TOLEDO, 2015) sendo o maior exemplo, talvez, a interpretação de Maria Bethânia para a canção Carcará de João do Vale, substituindo Nara Leão no Show opinião em $1965^{3}$.

Mutirão em Novo Sol é a peça que inaugura esse interesse na temática da arte engajada daqueles anos; não propriamente pela angulação rural, mas por tratar o tema pelo viés da luta de classes (VILLAS BÔAS, 2009, p. 68-87). E tal interesse iniciado com a peça revela tanto uma desconfiança ao projeto nacional-desenvolvimentista em marcha no país como uma atenção inédita para os conflitos de classe internos. Algo que, se verdade, problematiza as caracterizações históricas dualistas sobre a cultura pré-1964, na maior parte das vezes entendida como fiel depositária da ideologia desenvolvimentista e/ou premida por arroubos ingênuos de nacionalismo de esquerda à sombra do Partido Comunista Brasileiro (PCB).

A fração geográfica, social, histórica focalizada nas obras ganhava estatuto de imagem reduzida do país - seja sua face de barbárie perpétua, seja o horizonte de transformação que nossa sui generis luta de classes apresentava (ou escamoteava). Como sugere o marcante verso reiterado em Deus e o diabo na terra do sol: "o sertão vai virar mar/ o mar virar sertão". A peça Mutirão em Novo Sol também é decisiva historicamente na organização estrutural do texto, fundamentalmente sua inovadora tentativa de composição épica da dramaturgia. A forma tribunal na peça remete ao teatro político soviético e alemão das décadas de 1920 e 1930 e dá mostras da crescente influência que a leitura de Brecht e, fundamentalmente, de Erwin Piscator vinha exercendo nos jovens artistas politizados do período. Piscator, logo após a Primeira Guerra Mundial, criou o Teatro Tribunal (PISCATOR, 1968, p. 48-59), inspirado provavelmente em uma das

\footnotetext{
${ }^{3}$ A performance de Bethânia ficou eternizada em outro filme decisivo do período, O desafio de Paulo César Saraceni de 1965.
} 
modalidades mais disseminadas de agitprop soviético (o agitsud), que eram as representações em massa de julgamentos nos primeiros anos após a Revolução. Além disso, os tribunais e sua estrutura aparecem frequentemente nas peças de Brecht. Em Mutirão também o modelo brechtiano de teatro épico começou a ser experimentado, com canções, coros, narrativas, quebras de ação, comentários etc., em um tipo novo de composição dramatúrgica.

Por fim, o processo de escrita da peça realiza um gesto novo e decisivo no campo produtivo do teatro. A começar pelos procedimentos coletivos de composição - a partir de uma conversa com Jôfre no Teatro de Arena, o grupo organiza uma série de improvisações e debates sobre o tema que, por sua vez, tornam-se o material para a escrita. Cenas eram imaginadas, debatidas, improvisadas e então escritas. Algo que hoje parece natural foi um procedimento absolutamente novo no primeiro ano da década de 1960. E seu desenvolvimento esteve ligado, sobretudo, a um processo de intensa politização e questionamento dos paradigmas produtivos. A ideia de coletivo se desdobrou para o campo da criação - como já apontavam os Seminários de Dramaturgia do Arena.

Não é acaso, portanto, que montagens da peça entre 1961 e 1964 foram todas marcadas por um notável experimentalismo e tentativas de criar uma cena aberta e épica. A primeira delas foi organizada pelo CPC paulista, com direção de Chico de Assis, para ser apresentada no histórico I Congresso Nacional de Lavradores e Trabalhadores Agrícolas do Brasil (VERA, 1962, p. 95). O trabalho fundamentou-se em um tipo novo de trânsito entre pal- co e plateia, diferente de toda trajetória ligada à modernização do teatro no país; tratou-se de uma montagem aberta que ia se transformando a partir dos debates e apresentações. Segundo Juca de Oliveira $(2015)^{4}$, em entrevista aos pesquisadores do LITS: "Qualquer mudança, qualquer reação do público [...] resultaria numa modificação imediata do texto". É uma cena que marca uma nova concepção de teatro político, desenvolvida para ser apresentada em espaços fora do ambiente teatral, como sindicatos, congressos, encontros de lavradores etc., e que propõe como elemento central o trânsito vivo da cena com a plateia engajada. Ainda de acordo com Juca de Oliveira, tudo era pensado para que no momento das canções os camponeses participassem e cantassem junto, e, mesmo quando isso não ocorria, eles "participavam de uma forma total, absoluta".

Em 1962, Nelson Xavier montou o espetáculo com o Teatro de Cultura Popular (TCP) do Movimento de Cultura Popular (MCP) em Pernambuco. Com o título de Julgamento em Novo Sol, a estreia foi no Teatro Santa Isabel em Recife para um público de quase cinco mil pessoas, seguida de uma temporada no anfiteatro do MCP no bairro periférico de Casa Amarela. O enorme elenco com mais de 50 atores foi composto por jovens ligados ao Movimento - entre eles José Wilker em sua estreia no teatro -, e o espetáculo ficou marcado por uma cena moderna e épica, com coros e tentativas de composição experimental, como Germano Coelho recorda: "Havia cenas que lembravam esculturas movidas apenas pelo jogo de luz, como nos trabalhos de Eisenstein" (COELHO, 2002, p. 32).

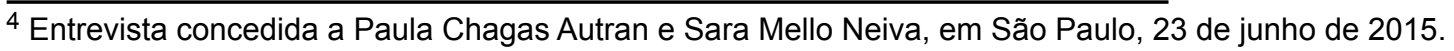


Ainda em 1962, em Salvador, Chico de Assis dirigiu uma montagem inovadora que uniu os setores de teatro, música e cinema do CPC da Bahia. O título do espetáculo foi Rebelião em Novo Sol. Concomitantemente ao processo de criação, Orlando Senna e Geraldo Sarno, dois jovens cineastas ligados ao CPC na época, gravaram um filme documentário sobre as Ligas Camponesas da Bahia que era projetado antes das apresentações. Também gravaram uma série de cenas que eram projetadas ao longo da peça e que, por vezes, contracenavam com os atores:

Além do documentário com meia hora de duração, que abria o espetáculo, também fizemos cenas documentais e ficcionais, soltas, para a composição multimídia. Por exemplo: em determinado momento, na tela de cinema sobre o palco, um pistoleiro dispara um tiro e um ator no palco, um camponês, é atingido. $O$ contraste entre a imagem gigante do pistoleiro na tela e a pequenez do camponês sozinho no palco era forte. (SENNA, 2008, p. 122-3)

A montagem híbrida e engajada foi algo bastante inovador para a arte política do período e, no limite, problematiza os estereótipos criados sobre o teatro participante produzido entre 1961 e 1964 - muitas vezes desqualificado como mera instrumentalização da arte em favor da política, portanto didático, simplório e artisticamente menor. O "acontecimento" Mutirão deve, portanto, ser visto como o conjunto entre dramaturgia com temática inovadora e experimentalismo épico das encenações.

O "esquecimento" de uma peça como Mutirão em Novo Sol dá provas da violência com que a ditadura militar não apenas interrompeu movimentos políticos e sociais, mas também, nas palavras de Paulo Arantes, "apagou até a memória de que um dia houve inconformismo de verdade no país" (ARANTES, 2010, p. 216). Em dezembro de 2015, no lançamento da publicação atual da peça, em edição organizada pelo Laboratório de Investigação em Teatro e Sociedade (LITS), Nelson Xavier, muito emocionado depois da leitura de cenas da obra, disse: "O Brasil viveu esse otimismo, a sensação de que tudo poderia ser diferente, as coisas eram vivas, depois veio o golpe e tudo terminou, eu nunca mais fui o mesmo, fiquei totalmente fragmentado, destruído". De fato, a interrupção abrupta provocada pelos militares apagou um tempo em que a arte deixou de ser vista como instituição neutra e supra-histórica e mobilizou recursos experimentais para desenvolver uma nova relação com a sociedade.

Referências

ARANTES, P. E. 1964, o ano que não terminou. In: TELES, E.; SAFATLE, V. (orgs.). O que resta da ditadura? São Paulo: Boitempo, 2010.

BETTI, M. S. Oduvaldo Vianna Filho. São Paulo: EDUSP, 1997

BOAL, A. Hamlet e o filho do padeiro. Rio de Janeiro: Editora Record, 2000.

Teatro do oprimido e outras poéticas políticas. Rio de Janeiro: Editora Civilização Brasileira, 1980.

CHAIA, V. L. M. Os conflitos de arrendatários em Santa Fé do Sul (1959-1969). 1980. Dissertação de Mestrado - Universidade de São Paulo, São Paulo, 1980. 
COELHO, G. Paulo Freire e o Movimento de Cultura Popular. In: ROSAS, P. (Org.). Paulo Freire: educação e transformação social. Recife: Editora da UFPE, 2002.

GUIMARÃES, C. Seminário de Dramaturgia: uma avaliação 17 anos depois. Revista Dionysos, Rio de Janeiro, nº 24, 1978.

MENDONÇA, L. Teatro é festa para o povo. Revista Civilização Brasileira, Rio de Janeiro, Caderno Especial 2: Teatro e Realidade Brasileira, p. 149-161, 1968.

PEIXOTO, F. (Org.). Vianinha. Teatro, Televisão, Política. São Paulo: Editora Brasiliense. 1983.

Entrevista com Gianfrancesco Guarnieri. In: Teatro em movimento. São Paulo: Hucitec, 1985.

PISCATOR, E. Teatro Político. Rio de Janeiro: Civilização Brasileira, 1968.

ROCHA, G. Revolução do Cinema Novo. Rio de Janeiro: Alhambra/Embrafilme, 1982.

SANTOS, J. O. Mutirão em Novo Sol no $1^{\circ}$ Congresso Nacional de Camponeses. Revista Brasiliense, São Paulo, nº. 39, p. 173-175, jan./ fev. 1962.

SENNA, O. O homem da montanha. São Paulo: Imprensa Oficial, 2008.

TOLEDO, P. B. A ambivalência do protesto no teatro e na canção no Brasil pós-1964. Sala Preta, São Paulo, v. 15, n. 1, p. 180-190, jul. 2015. Disponível em: <http://www.revistas.usp. br/salapreta/article/view/96014>. Acesso em: 14 ago. 2015. DOI: http://dx.doi.org/10.11606/ issn.2238-3867.v15i1p180-190.

VERA, N. O congresso camponês em Belo Horizonte. Revista Brasiliense, São Paulo, n. 39, p. 94-99, jan./fev. 1962.

VILLAS BÔAS, R. L. Teatro político e questão agrária, 1955-1965: contradições, avanços e impasses de um momento decisivo. 2009. Tese de Doutorado - Universidade de Brasília, Brasília, 2009.

WELCH, C. A. Jôfre Corrêa Netto: capitão camponês (1921-2002). São Paulo: Expressão Popular, 2010.

XAVIER, N. Mutirão em Novo Sol. São Paulo: Expressão Popular, 2015.

Recebido em 07/12/2015. Aprovado em 25/05/2016. 